\title{
Synthesis of Poly(ethylene terephthalate-co-isophthalate) by Copolymerization of Ethylene Isophthalate Cyclic Dimer and Bis(2-hydroxyethyl) Terephthalate
}

\author{
Ritsuko Nagahata, ${ }^{\dagger}$ Jun-ichi SugiYama, Sivan Velmathi, Yukimichi NaKao, \\ Midori GOTO, and Kazuhiko TAKEUCHI
}

National Institute of Advanced Industrial Science and Technology (AIST),

AIST Tsukuba Central 5, 1-1-1, Higashi, Tsukuba, Ibaraki 305-8565, Japan

(Received January 20, 2004; Accepted April 7, 2004; Published June 15, 2004)

\begin{abstract}
Ethylene isophthalate cyclic dimer (EI $c$-2mer) and bis(2-hydroxyethyl) terephthalate (BHET) were successfully copolymerized in the bulk state by microwave heating to give a polymer with $M_{\mathrm{w}}>20000$. Terminal functionalities of the copolymers obtained were investigated by the MALDI-TOF mass analysis technique. The first stage of the copolymerization reaction involves homopolymerization of BHET. In the second stage, reactive end-group of poly(ethylene terephthalate) or BHET itself can attack the EI $c$-2mer and gradually produce an EI-terminated copolymer. In the third stage, the propagation reaction of EI-terminated copolymer occurs through the three types of elementary reaction route. [DOI 10.1295/polymj.36.483]

KEY WORDS Copolymerization / MALDI / Microwave / Polyesters / Ring-opening Polymerization /
\end{abstract}

New routes to polyesters through environmentally friendly, ring-opening polymerization of macrocyclic oligomers have been attracting increasing attention from researchers. ${ }^{1-6}$ We have demonstrated that thermal ring-opening polymerization of cyclic oligocarbonates or cyclic oligo(ethylene terephthalate) gives high-quality polymers. ${ }^{7,8}$ Macrocyclic precursors containing strained small-ring moieties undergo solidstate ring-opening polymerization at temperatures considerably below their melting points. Macrocyclic oligomers with a low strain in the ring undergo simultaneous growth reaction of the polymer chain and transesterification, which interferes with formation of high-molecular weight polymers. In the case of the synthesis of poly(ethylene terephthalate) (PET), although the macrocyclic ethylene terephthalate dimer would appear to be the most suitable for our requirements, no simple and effective method for its selective synthesis has been reported in the literature. Recently, we have developed a novel method for the selective synthesis of ethylene isophthalate cyclic dimer (EI $c$-2mer). ${ }^{9}$ In comparison with the ethylene terephthalate dimer, this compound is easily formed because of its stable molecular structure. Isophthalate is known to be an important comonomer unit in other aromatic polyesters [PET, poly(butylene terephthalate, poly(ethylene naphthalate), etc.]. ${ }^{10}$ In this report we investigate the application of EI $c$-2mer as a precursor of copolymers.

\section{EXPERIMENTAL}

Crystal Data for EI c-2mer

$\mathrm{C}_{20} \mathrm{H}_{16} \mathrm{O}_{8}, \quad M_{\mathrm{w}}=384.34$, crystal size $0.20 \times$ $0.20 \times 0.20 \mathrm{~mm}$, triclinic, space group P1-(\#2) $a=$ 7.6726(8), $b=9.6740(8)$, and $c=6.1568(5) \AA, \alpha=$ 101.310(7), $\beta=95.096(8)$, and $\gamma=107.202(7)^{\circ}$, $V=422.78(7) \AA^{3}, Z=1, D_{\text {calcd }}=1.509 \mathrm{~g} / \mathrm{cm}^{3}$. The intensity data were collected on a Rigaku AFC7R diffractometer with graphite-monochromated Mo- $K \alpha$ radiation, $\lambda(\operatorname{Mo} K \alpha)=0.71069 \AA$, $\omega$-scan, $\mu=1.18$ $\mathrm{cm}^{-1}, 2117$ measured $(-9 \leq h \leq 9,-12 \leq k \leq 12$, $\left.-7 \leq l \leq 0,2 \theta_{\max }=55.0^{\circ}\right)$ and 1935 unique reflections $\left(R_{\text {int }}=0.01\right)$. The structure was solved by a direct method (SIR92). ${ }^{11}$ All unique observed 1935 reflections were used for the refinement (refinement on $F^{2}$, number of parameters $=127$ ). The positions of hydrogen atoms were calculated as ideal positions and their positions were not refined. $R_{1}=0.035$ $(I \geq 2.00 \sigma(I)) ; R_{\mathrm{w} 2}=0.113\left(w=1 / \sigma^{2}\left(F_{\mathrm{o}}\right)\right)$. Residual electron density: $0.17,-0.18 \mathrm{e}^{-3}$. All calculations were performed by using the crystallographic software package teXsan 1.9 [Molecular Structure Corporation (1985 \& 1999)].

\section{Other Measurements}

Gas chromatography (GC) data were collected by using an Agilent model 6890 coupled with a HP-5 fused silica column $(30 \mathrm{~m} \times 0.32 \mathrm{~mm} \times 0.25 \mu \mathrm{m})$

${ }^{\dagger}$ To whom correspondence should be addressed (E-mail: nagahata-ritsuko@aist.go.jp). 
and a flame-ionization detector. Size-exclusion chromatography (SEC) analyses were carried out with a JASCO Gulliver system coupled with a Shodex K804L column and an ultraviolet detector set at $254 \mathrm{~nm}$. The mobile phase was chloroform and data were recorded at $35^{\circ} \mathrm{C}$ at flow rate of $1 \mathrm{~mL} / \mathrm{min}$. Polymer samples were dissolved in $50 \%$ (v/v) hexafluoropropan-2-ol (HFIP)/chloroform and the solutions were diluted 25 times with chloroform and injected. Samples for mass spectrometric analyses were collected by SEC fractionation. A $0.5-\mathrm{mL}$ portion of the SEC elute for each fraction was dried before the mass analyses. A matrix-assisted laser desorption/ionization time-of-flight (MALDI-TOF) mass spectrometer (Bruker Daltonics Reflex III) equipped with a nitrogen laser $(l=337 \mathrm{~nm})$ in reflectron mode was used for the analysis of the molecular structures of the polymerization products. 2-(4-Hydroxyphenylazo)benzoic acid $(30 \mathrm{mg} / \mathrm{mL})$ in tetrahydrofuran (THF) was used as the matrix. Solutions of the fractionated samples were prepared in HFIP at a concentration of about $1 \mathrm{mg} / \mathrm{mL}$, and then mixed in a ratio of $1: 10$ by volume with the fractionated sample/matrix. Data processing for calculating diethylene glycol (DEG) levels was performed by using XTOF version 5.0 (Bruker Daltonics K.K.). ${ }^{1} \mathrm{H}$ NMR spectra were obtained on a JEOL LA600 in 1,1,2,2-tetrachloroethane- $d_{2}$ with tetramethylsilane as an internal standard.

\section{Ring-opening Polymerization of EI c-2mer}

The starting material was finely ground by a pestle and a mortar before use. Typically, $50 \mathrm{mg}$ of the mixture of EI $c$-2mer, bis(2-hydroxyethyl) terephthalate (BHET), and 1,3-dichloro-1,1,3,3-tetrabutyldistannoxane (distannoxane) catalyst were placed in a ceramic vessel on the rotating disk of a conventional multimode microwave oven (Toshiba ER-VS1) and irradiated at $500 \mathrm{~W}$ for the required time. For comparison, experiments with conventional heating were carried out with an oven at $200^{\circ} \mathrm{C}$. Average molecular weights of the polymerization products were determined by SEC with polystyrene as a standard. Compositions of the polymers were determined by ${ }^{1} \mathrm{H}$ NMR spectrometry and MALDI mass spectrometry.

\section{Materials}

EI $c$-2mer was synthesized from ethylene glycol diacetate and isophthalic acid dimethyl ester through the ester-ester exchange method. ${ }^{9}$ Recrystallization from DMF produced white crystals of mp 390-401 ${ }^{\circ} \mathrm{C}$. The distannoxane was kindly supplied by Nitto Denko Corp. (Japan) and used as received. Other reagents were all first-grade and used without further purification.

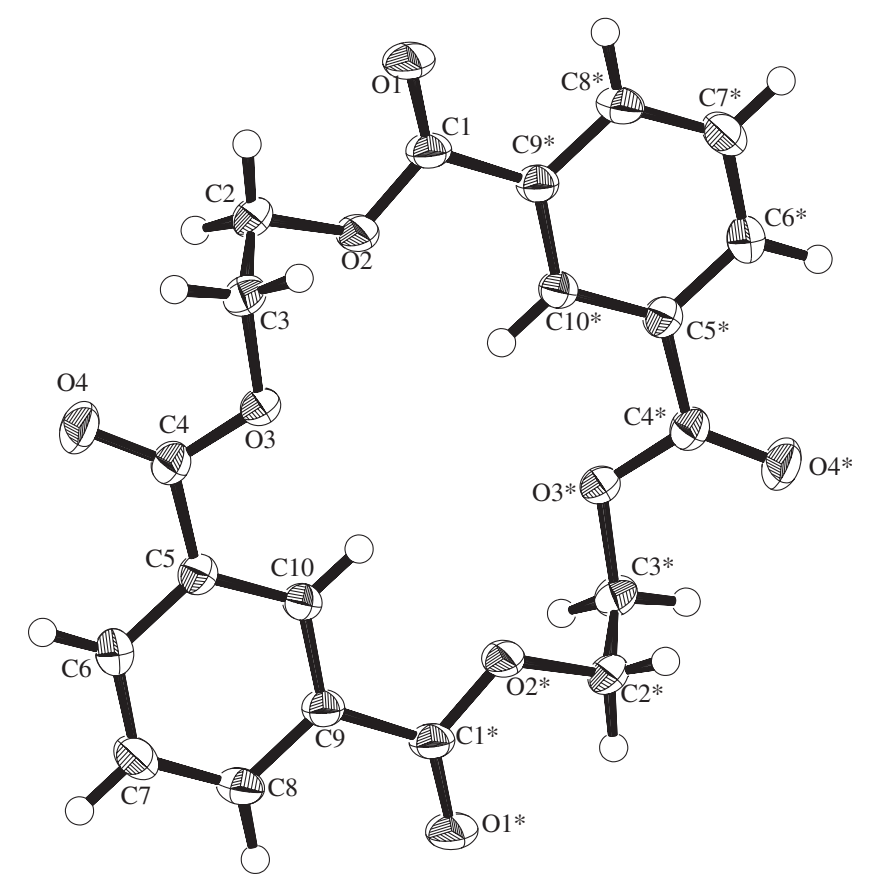

Figure 1. X-Ray structure of EI $c$-2mer.

\section{RESULTS AND DISCUSSION}

Single crystal X-Ray diffraction data of EI $c$-2mer were analyzed as shown in Figure 1. The unit cell contains one centrosymmetrical molecule. The planes of the two benzene rings are parallel. Both ethylene glycol moieties (EGs) have torsion angles of $56.4^{\circ}$ and are arranged in a near-gauche configuration. Apparently, the disk-shape molecules are piled on top of one another in a compact manner. This result supports the distinctive nature of EI $c$-2mer, namely, its high melting point and high crystallinity. Furthermore, we suspected that EI $c$-2mer would have a little ability to undergo homopolymerization.

Conventional heating (without microwave irradiation) was carried out at $200^{\circ} \mathrm{C}$, because the temperature of the reaction vessels just after microwave irradiation was about $200^{\circ} \mathrm{C}$. Table I shows results relating to the polymerization of EI $c$-2mer with BHET comonomer. After attempts at homopolymerization of EI $c$-2mer with or without microwave irradiation (runs 1-3), no polymeric products were observed on SEC analyses after heating for $60 \mathrm{~min}$. In investigations of copolymer synthesis, BHET was selected as the comonomer owing to its practical uses (Scheme 1). Conventional heating of a mixture of EI $c$-2mer and BHET (50:50 molar) with $1.0 \mathrm{~mol} \%$ of the distannoxane at $200{ }^{\circ} \mathrm{C}$ for $60 \mathrm{~min}$ resulted in a low-molecular weight copolymer with $M_{\mathrm{w}} 5900$ $\left(M_{\mathrm{w}} / M_{\mathrm{n}} 3.0\right.$, run 4$)$. On the other hand, heating by microwave irradiation instead of conventional heating accelerated the polymerization to afford a copolymer 
Synthesis of Poly(ethylene terephthalate-co-isophthalate)

Table I. Results of polymerization of EI $c$-2mer and BHET

\begin{tabular}{cccccccc}
\hline Run & $\begin{array}{c}\text { EI } c-2 \text { mer/BHET } \\
(\text { mol ratio })\end{array}$ & $\begin{array}{c}\text { Conc. of } \\
\text { distannoxane } \\
(\mathrm{mol} \%)\end{array}$ & $\begin{array}{c}\text { Microwave } \\
\text { irradiation }\end{array}$ & $\begin{array}{c}\text { Temp. } \\
\left({ }^{\circ} \mathrm{C}\right)\end{array}$ & $\begin{array}{c}\mathrm{Time}^{\mathrm{b}} \\
(\mathrm{min})\end{array}$ & $M_{\mathrm{w}}{ }^{\mathrm{c}}$ & $M_{\mathrm{w}} / M_{\mathrm{n}}{ }^{\mathrm{c}}$ \\
\hline 1 & $100 / 0$ & 1.0 & off & 200 & 60 & - & - \\
2 & $100 / 0$ & 1.0 & on & $193-196$ & 60 & - & - \\
3 & $100 / 0$ & 0 & off & 200 & 60 & - & - \\
4 & $50 / 50$ & 1.0 & off & 200 & 60 & 5900 & 3.0 \\
5 & $50 / 50$ & 1.0 & on & $193-196$ & 30 & 8400 & 2.4 \\
6 & $50 / 50$ & 1.0 & on & $193-196$ & 60 & 20900 & 3.1 \\
7 & $50 / 50$ & 0 & on & $193-196$ & 30 & 400 & 1.5 \\
8 & $50 / 50$ & 0 & on & $193-196$ & 60 & 900 & 2.1 \\
\hline
\end{tabular}

${ }^{a}$ The temperature in conventional heating (microwave off) was measured at the surface of the reaction vessels just after heating. ${ }^{\mathrm{b}}$ In the conventional heating experiments, the heating time was recorded from the point when the reaction temperature was attained. ${ }^{c}$ Estimated by SEC (based on a polystyrene standard) with a range from monomer to polymer in one pass.

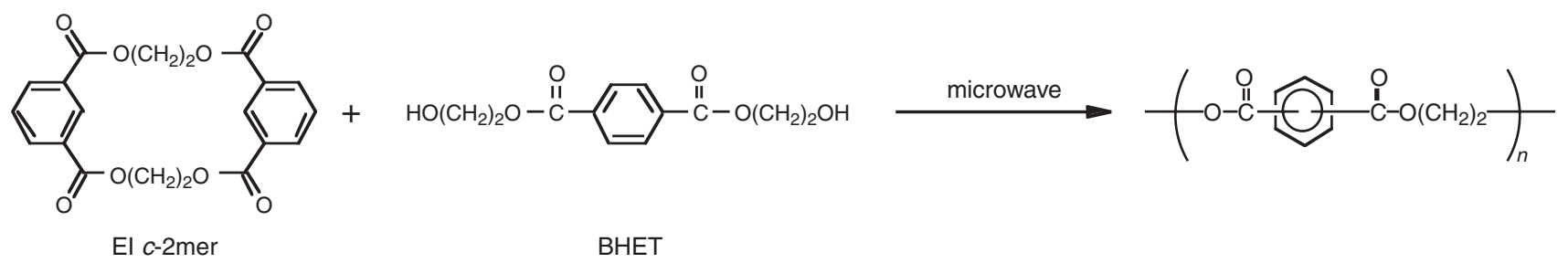

Scheme 1. New synthetic route to poly(ethylene terephthalate-co-isophthalate) by microwave-assisted copolymerization.

with a $M_{\mathrm{w}}$ of $8400\left(M_{\mathrm{w}} / M_{\mathrm{n}}=2.4\right)$ after $30 \min ($ run 5). On prolonging the microwave irradiation time to $60 \mathrm{~min}$, the degree of polymerization was increased and a copolymer with a $M_{\mathrm{w}}$ of $20900\left(M_{\mathrm{w}} / M_{\mathrm{n}}=\right.$ 3.1) was obtained (run 6). The products were colorless solids and were soluble in HFIP or 50\% (v/v) HFIP/ chloroform. In the absence of the catalyst, and irrespective of the method of heating, only small amounts of polymeric materials with a low molecular weight were detected by SEC (runs 7, 8). Although a small new peak for the polymer appeared on the chromatograms, the peaks for the raw material remained practically unchanged. Therefore, it is necessary to add a suitable Lewis acid catalyst to activate the ester group of the EI $c$-2mer.

Figure 2 shows typical MALDI-TOF mass spectra of the fractionated samples. The spectrum (a) corresponds to the region of relatively high molecular weights (6000-18000), which mainly exhibited three series of ion peaks at $m / z \quad 192.17 n+\alpha$ where 192.17 is the mass of the repeat unit of poly(ethylene isophthalate) (PEI) or PET, $n$ is the number of repeat units, and $\alpha$ represents the residual mass of the endgroups and adducted cation. The main series (marked A) were identified as ions corresponding to $\mathrm{M}+\mathrm{Na}^{+}$, where $\mathrm{M}$ is the bis-hydroxy-terminated PEI/PET copolymer. Spectra of ions of the other series (marked $\mathrm{B}$ and $\mathrm{C}$ ) correspond to linear polymeric chains with the same end group as A that have one or two DEG defects, respectively.

The spectra (b) and (c) are examples of mediummolecular weight regions (b: 4000-8000, c: 20006000) that also exhibited A and B series. Spectrum (d) corresponds to the lowest molecular weight region (1000-4000). Peaks marked D were particularly prominent in this region and these were identified as corresponding to ionized cyclic polymers. Degrees of DEG defects were given by solving the following quadratic equations by using the binomial theorem:

$$
\begin{aligned}
& x+y=1 \\
& \frac{\text { intensity of peak A }}{{ }_{n} \mathrm{C}_{0} x^{n-0} y^{0}}=\frac{\text { intensity of peak B }}{{ }_{n} \mathrm{C}_{1} x^{n-1} y^{1}}
\end{aligned}
$$

where $n$ is degree of polymerization, $x$ is the ratio of $\mathrm{EG}$, and $y$ is the ratio of DEG. Table II shows the calculated results; these indicate DEG levels are around $1-2 \%$ in every molecular-weight region. In the case of the 55mer, peak C could also be use for the calculation. The absolute intensity of the peak $(\mathrm{m} / \mathrm{z}=$ 10745.5) was 1769: solving the equations resulted in a value of $1.4 \%$ DEG defect, which agreed well with the solution for the 55mer in Table II. The quantity of DEG in PET molecules influences many important properties of the polymer; for instance its temperature, light stability, and melting point (which decreases by about $5{ }^{\circ} \mathrm{C}$ for each percentage point of DEG concentration). ${ }^{12}$ DEG has been extensively studied for a 

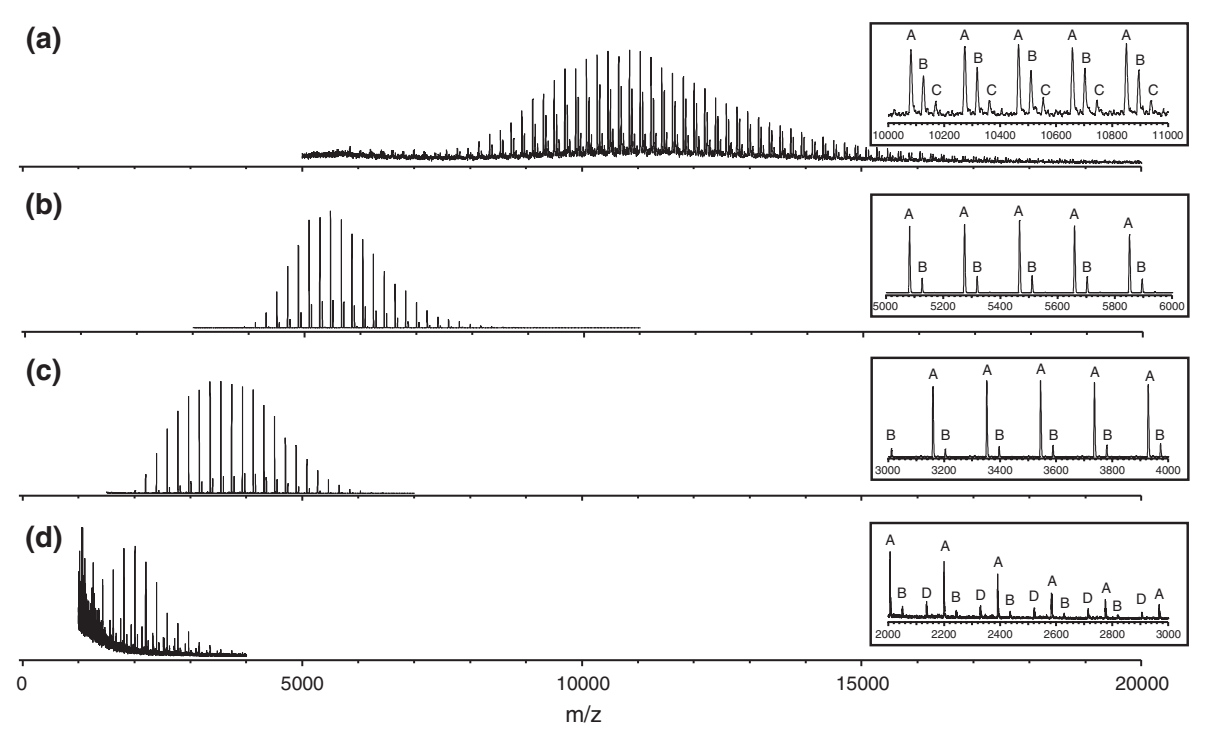

Figure 2. Positive-ion MALDI-TOF mass spectra of: (a) SEC fraction 1 (molecular weight 6000-18000), (b) SEC fraction 2 (molecular weight 4000-8000), (c) SEC fraction 3 (molecular weight 2000-6000), (d) SEC fraction 4 (molecular weight 1000-4000). All spectra were recorded in reflection mode using 2-(4-hydroxyphenylazo)benzoic acid as the matrix.

Table II. Diethylene glycol (DEG) levels in the fractionated polymer samples calculated from intensity values of MALDI-TOF MS peaks

\begin{tabular}{|c|c|c|c|c|c|}
\hline \multirow{2}{*}{$\begin{array}{l}\text { Degree of polym. } \\
(n)\end{array}$} & \multicolumn{2}{|c|}{ Peak A } & \multicolumn{2}{|c|}{ Peak B } & \multirow{2}{*}{$\begin{array}{c}\text { DEG level } \\
(\%)\end{array}$} \\
\hline & $\operatorname{mass}^{\mathrm{a}}(m / z)$ & abs. intensity ${ }^{b}$ & $\operatorname{mass}^{\mathrm{c}}(m / z)$ & abs. intensity ${ }^{\mathrm{b}}$ & \\
\hline 10 & 2006.7 & 1510 & 2050.9 & 340 & 2.2 \\
\hline 20 & 3928.6 & 1233 & 3972.7 & 229 & 0.9 \\
\hline 30 & 5851.2 & 576 & 5895.3 & 136 & 0.8 \\
\hline 55 & 10658.0 & 5951 & 10702.4 & 4337 & 1.3 \\
\hline
\end{tabular}

${ }^{\mathrm{a}} m / z$ (theoretical $)=192.17 n+85.06 .{ }^{\mathrm{b}}$ All the peaks concerned were identified by the centroid method and estimated by absolute intensities. ${ }^{c} m / z$ (theoretical) $=192.17 n+129.11$.
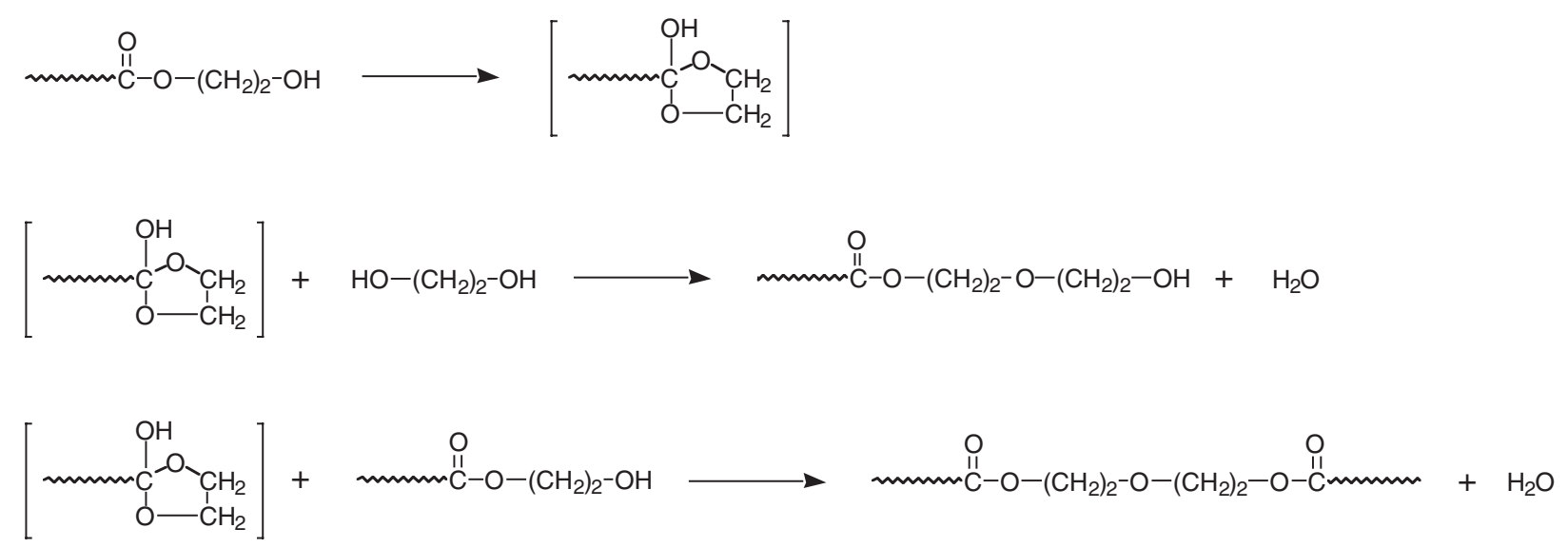

Scheme 2. Possible mechanisms of formation of DEG defects in the polymer chain or at its end that proceed via a five-membered transition state.

considerable time. ${ }^{13-17}$ Scheme 2 shows possible mechanisms for the formation of DEG defects in the polymer chain or at its ends, which proceed via a five-membered transition state. This intermediate reacts with EG to give a terminal DEG moiety or with a hydroxyethyl end-group to give an internal DEG moiety. Other routes to the formation of DEG have been proposed by other researchers, ${ }^{13-17}$ but those involve polymer structures with carboxyl or vinyl endgroups. Such structures were not detected by the MALDI-TOF mass analysis in this case. Another possibility is that free dimer (DEG) generated by conden- 

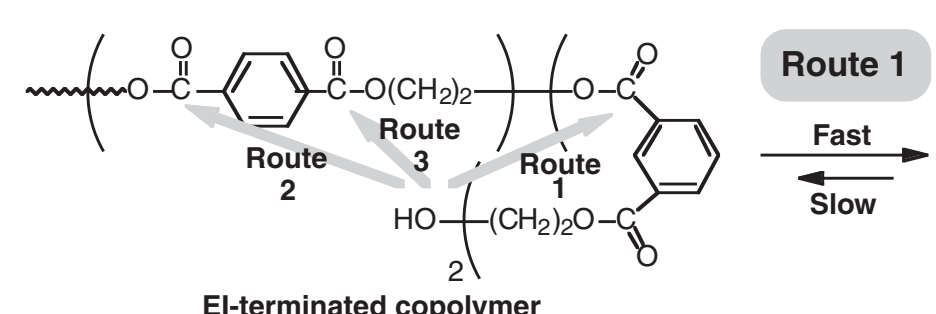

El-terminated copolymer
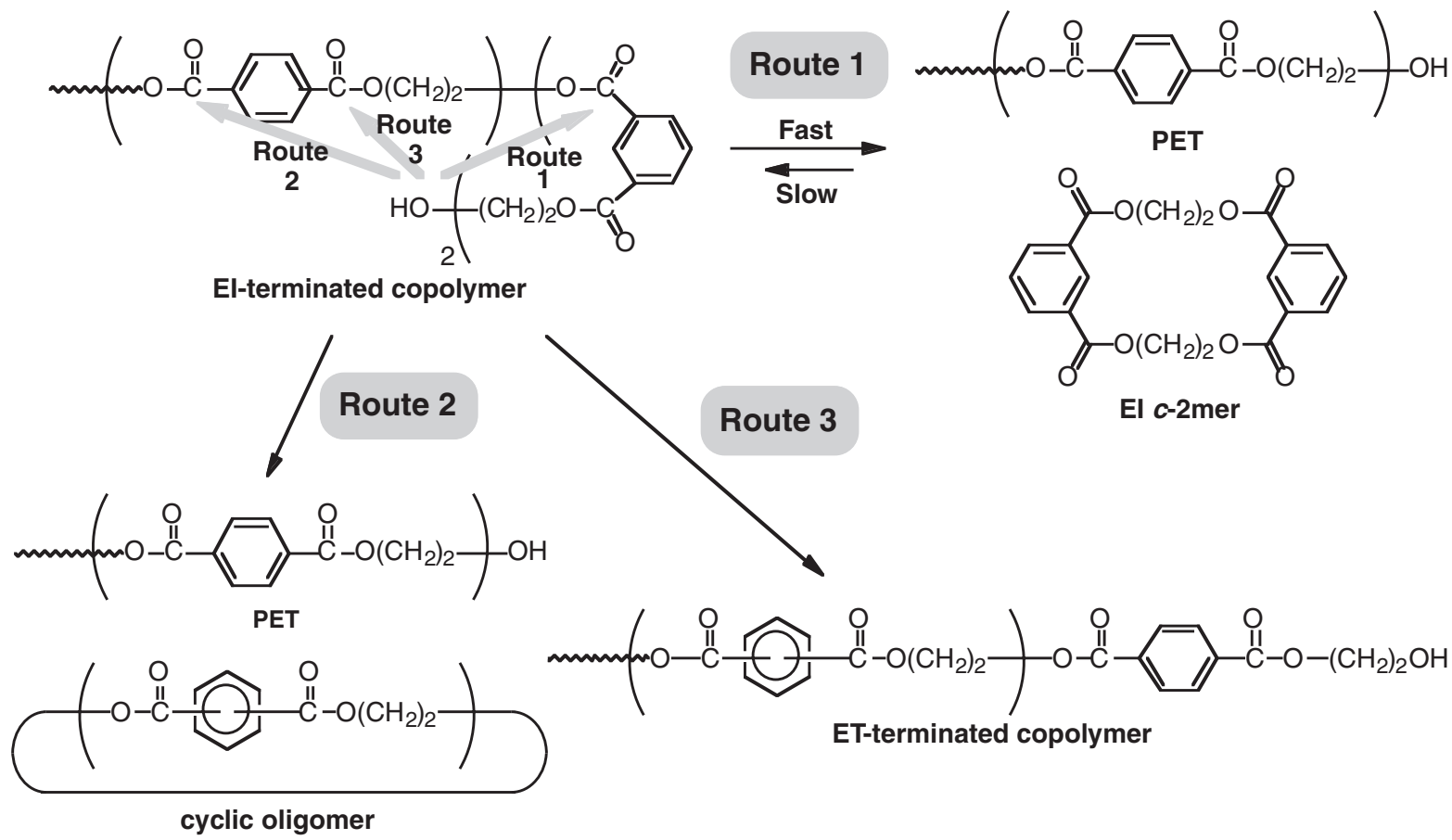

El c-2mer

Scheme 3. Propagation reaction of EI-terminated copolymer occurring through the three types of elementary reaction route.

sation of EG takes part in forming the polymer defect.

In the case of the polymer obtained from run 6 , the copolymer composition was calculated to be $40: 60$ (EI:ET) by the integration of aromatic protons peaks of the ${ }^{1} \mathrm{H}$ NMR spectrum. This deficiency in EI composition is thought to be the result of later conversion of EI $c$-2mer and sublimation. Actually, from GC analysis of the polymer obtained from run 6 , the converted EI $c$-2mer was determined to be $95.9 \mathrm{~mol} \%$ and BHET was not detected.

To compare the copolymerization rates of EI $c$ 2 mer and BHET, the amounts of unreacted raw materials were determined by GC for some experiments. Conventional heating of a mixture of EI $c$-2mer and BHET $(50 / 50 \mathrm{~mol} \%)$ with $1.0 \mathrm{~mol} \%$ of the distannoxane at $200^{\circ} \mathrm{C}$ for $60 \mathrm{~min}$ (run 4), gave a material of $M_{\mathrm{w}} 5900$ that did not include any unreacted BHET, but contained $54.7 \%$ of EI $c$-2mer. On microwave irradiation for $30 \mathrm{~min}$ with the catalyst (run 5), $16.3 \%$ of EI $c$-2mer remained and the average molecular weight of the polymer was no more than $8400\left(M_{\mathrm{w}}\right)$. In the case of microwave irradiation without the distannoxane for 60 min (run 8), $100 \%$ of EI $c$-2mer was recovered despite an $80.7 \%$ conversion of BHET. This result shows the difficulty of performing the ringopening reaction of the EI $c$-2mer without activating the carbonyl groups with a Lewis acid catalyst.

From the overall experimental results, we found that homopolymerization of BHET occurs independently in the first stage of the copolymerization reaction. In the second stage, reactive end-group of PET or BHET attack the EI $c$-2mer and gradually produce
EI-terminated copolymer. In the third stage, the propagation reaction of the EI-terminated copolymer occurs through the three types of elementary reaction route (Scheme 3). Part of the EI-terminated copolymer is converted back to PET and EI $c$-2mer through the backbiting reaction with the smallest turning circle (Route 1). The existence of this route is supported by the experimental result that homopolymerization of EI $c$-2mer is difficult to perform (runs 1-3). The other two routes are thought to occur with equal probabilities. Of these reactions, the backbiting reactions with larger turning circles are induced on both sides of the dicarboxylic acid moiety. Depending on the site $(-\mathrm{O}-\mathrm{CO}-$ or $-\mathrm{CO}-\mathrm{O}-)$, different types of the product are obtained. From one route (Route 2), a linear polymer and a cyclic oligomer are produced, as already identified by MALDI-TOF mass analysis [peaks D in Figure 2(d)]. In the other route (Route 3), rearrangement of the polymer chain occurrs to form ET-terminated copolymer. It is impossible to determine the copolymer composition by MALDI-TOF mass analysis because the mass numbers of the EI and ET units are the same. However, the existence of cyclic species indirectly supports the existence of this route. This ET-terminated copolymer has the ability to attack carbonyl groups of other cyclic or linear compounds. In this way, poly(ethylene terephthalate$c o$-isophthalate) with a higher molecular weight is obtained in the later stages of the reaction.

In summary, a new method was developed for synthesizing poly(ethylene terephthalate-co-isophthalate) from EI $c$-2mer and BHET. In this study, BHET 
was used as a model for polyesters with glycol endgroups. Applications to polyester oligomers and polymers other than BHET may give copolymers with a higher molecular weight and a lower DEG content. Further studies to elucidate the effects of microwave heating are now under way.

Acknowledgment. The authors would like to acknowledge experimental contributions from Professor T. Hagiwara and Mr. H. Hirata (Saitama Institute of Technology, Japan). The authors thank Dr. A. Nishio (Nitto Denko Corp., Japan) for his material support. This study was carried out as a part of the 'Nanostructure Polymer Project' supported by the New Energy and Industrial Technology Development Organization (NEDO) launched in 2001.

\section{REFERENCES}

1. P. Hubbard, W. J. Brittain, W. J. Simonsick, Jr., and C. W. Ross, III, Macromolecules, 29, 8304 (1996).

2. a) D. J. Brunelle, J. E. Bradt, J. Serth-Guzzo, T. Takekoshi, T. L. Evans, and E. J. Pearce, Polym. Prepr. (Am. Chem. Soc., Div. Polym. Chem.), 38, 381 (1997).

b) P. A. Hubbard, W. J. Brittain, W. L. Mattice, and D. J. Brunelle, Macromolecules, 31, 1518 (1998).

c) D. J. Brunelle, J. E. Bradt, J. Serth-Guzzo, T. Takekoshi, T. L. Evans, E. J. Pearce, and P. R. Wilson, Macromolecules, 31, 4782 (1998).

3. a) J. J. L. Bryant and J. A. Semlyen, Polymer, 38, 2475 (1997).

b) J. J. L. Bryant and J. A. Semlyen, Polymer, 38, 4531 (1997).

c) S. C. Hamilton, J. A. Semlyen, and D. M. Haddleton, Polymer, 39, 3241 (1998).

4. a) P. Hodge, Z. Yang, A. Ben-Haida, and C. S. McGrail, J. Mater. Chem., 10, 1533 (2000).

b) A. J. Hall, P. Hodge, C. S. McGrail, and J. Rickerby,
Polymer, 41, 1239 (2000).

5. R. R. Burch, S. R. Lustig, and M. Spinu, Macromolecules, 33, 5053 (2000).

6. a) J. H. Youk, R. P. Kambour, and W. J. MacKnight, Macromolecules, 33, 3594 (2000).

b) J. H. Youk, A. Boulares, R. P. Kambour, and W. J. MacKnight, Macromolecules, 33, 3600 (2000).

c) J. H. Youk, R. P. Kambour, and W. J. MacKnight, Macromolecules, 33, 3606 (2000).

7. a) R. Nagahata, J. Sugiyama, M. Goyal, M. Asai, M. Ueda, and K. Takeuchi, Polym. Adv. Technol., 11, 294 (2000).

b) R. Nagahata, J. Sugiyama, M. Goyal, M. Goto, M. Asai, M. Ueda, and K. Takeuchi, Polym. Adv. Technol., 11, 727 (2000).

c) R. Nagahata, J. Sugiyama, M. Goyal, M. Asai, M. Ueda, and K. Takeuchi, Polym. J., 32, 854 (2000).

8. a) R. Nagahata, J. Sugiyama, M. Goyal, M. Asai, M. Ueda, and K. Takeuchi, J. Polym. Sci., Part A: Polym. Chem., 38, 3360 (2000).

b) R. Nagahata, J. Sugiyama, M. Goyal, M. Goto, K. Honda, M. Asai, M. Ueda, and K. Takeuchi, Polymer, 42, 1275 (2001).

9. R. Nagahata, J. Sugiyama, Y. Nakao, M. Asai, and K. Takeuchi, Macromolecules, 36, 2582 (2003).

10. G.-H. Hsiue, T.-S. Yeh, and S. Chang, J. Appl. Polym. Sci., 37, 2803 (1989).

11. A. Altomare, M. Cascarano, C. Giacovazzo, A. Guagliardi, M. C. Burla, G. Polidori, and M. Camalli, J. Appl. Crystallogr., 27, 435 (1994).

12. J. M. Besnoin and K. Y. Choi, J. Macromol. Sci., Polym. Rev., 29, 55 (1989).

13. a) L. H. Buxbaum, Angew. Chem., 80, 225 (1968).

b) L. H. Buxbaum, Angew. Chem., Int. Ed., 7, 182 (1968).

14. K. Yoda, Kobunshi Kagaku, 24, 472 (1967).

15. H. R. Reimschuessel, Ind. Eng. Chem. Prod. Res. Dev., 19, 117 (1980).

16. H. Renwen, Y. Feng, H. Tinzheng, and G. Shiming, Angew. Makromol. Chem., 119, 159 (1983).

17. S. G. Hovenkamp and J. P. Munting, J. Polym. Sci., Part A: Polym. Chem., 8, 679 (1970). 